Discourse and Communication for Sustainable Education, vol. 11, no. 2, pp. 20-32, 2020

\title{
Sustainable Design Education - An Evaluation of an International Student Design Workshop in Hanoi, Vietnam
}

\author{
Phan Anh Nguyen, Regina Bokel, and Andy van den Dobbelsteen \\ Delft University of Technology, Delft, the Netherlands
}

\begin{abstract}
Green Architecture for Sustainable Communities (GASC) was a joint event organised by Dutch and Vietnamese universities with the aim of boosting sustainable development in the built environment of Vietnam. As a key activity of the event, the international student design workshop focused on renovation of typical Vietnamese row houses aiming towards sustainable and energy efficient homes. This study reports an evaluation of the student workshop based on a post-workshop questionnaire and the outcomes of the student groups. Results showed that most activities were successful in transferring sustainable knowledge to the students. The students were capable of learning sustainable theory, analysing suitable design strategies in the specific cases and applying that knowledge into the design proposals. Students learned more about bioclimatic designs and related topics such as daylight, natural ventilation, indoor comfort and greenery. Sustainable aspects of energy efficiency and water usage were also of great interest. The student selection process was the main issue for this workshop. For future events, more involvement of architects with practice is recommended.
\end{abstract}

Key words: sustainability, design education, student workshop, constructive alignment, Vietnam.

\section{Introduction}

Sustainability in the built environment can only be achieved when different parties are involved and take action. In Vietnam, legislative and institutional challenges are often perceived as the biggest obstacles to sustainable buildings. However, social and cognitive barriers were presented as the main problems that hinder the development of green and sustainable architecture (Nguyen et al., 2017). In recent years, green buildings and sustainable homes in Vietnam are mostly the products of a new generation of architects. Therefore, as in educational institutions, inspiring and teaching architecture students how to design sustainable architecture is an important mission.

Green Architecture for Sustainable Communities (GASC) was an event organised by Delft University of Technology (TUD) and two Vietnamese universities: Hanoi Architectural University (HAU) and National University of Civil Engineering (NUCE) 
with the aim of boosting sustainable development in the built environment of Vietnam. This event aimed at transferring the latest theoretical and practical sustainability knowledge from the international experts to the architecture students. Different activities, including a symposium, a design workshop and several discussion panels on sustainability topics, were held simultaneously within a one-week period. Continuing the success of GASC 2017, GASC 2019 took place in Hanoi, the capital of Vietnam. The event was held from the $15^{\text {th }}$ to the $20^{\text {th }}$ of September 2019. This time, the symposium and design workshop focused on the design strategies for energy efficiency in private urban houses so called "tube houses" in Vietnam - aiming for zero-energy homes.

During the workshop, students were given information through several sources, including research papers, scientific and practical lectures, and design studio guidance. They also had extensive discussions and feedback within and across the groups. This paper aims to investigate what the students learned and how they gained knowledge and skills of designing sustainable architecture.

\section{Design Education}

Designing is often considered as a complex skill, which is personal, creative and open-ended (Dreyfus et al., 2000). Teaching and learning of this skill follow the conception of the design process. In design education, teachers are often master practitioners who know the operating skills, ways of thinking and communicating, where novice students want to learn these moves and design vocabularies (Waks, 2001). Although designing is often an implicit activity (Dreyfus et al., 2000; Lawson, 2006), researchers have shown that making an idea or concept explicit is important in design education (Kolb, 2014; Reigeluth, 1983). It is important that teachers and students often talk about the design process in the studio. Five generic elements were defined to help the tutors and students making content explicit in the design learning process. They are: experimenting or exploring and deciding, guiding themes or qualities, domains, frame of reference or library, laboratory or visual language (van Dooren et al., 2014).

The traditional way of design education is done through design studios and this is still an effective way to help the student learn design skills (Cross, 1982). Sustainable architecture programmes often combine the studio with workshops and lectures on sustainable and climate design (Dobbelsteen \& Linden, 2007). Another effective way of learning, used for smart and bioclimatic design, is self-directed learning, where the students can choose a specific sustainability topic to study and use this information to create their own design manuals (Dobbelsteen \& Linden, 2007).

In GASC 2019, the student design workshop combined the design studio with sustainability lectures, and architect talks, which were given during the conference. With help from the universities' teachers, intensive discussions and guidance were conducted daily. The students, however, did not have time for a design manual, but they were free to study sustainable design strategies and decide their own approaches.

The students were guided with a holistic approach to sustainable design, including ecological, technical and social aspects. In terms of ecology, main topics discussed were bioclimatic design, greenery, daylight, indoor thermal comfort, natural ventilation, acoustics and air quality. The technical part covered energy efficiency, water usage and materials. Local culture and user behaviour were mentioned as the social aspect of sustainability (Heasly et al., 2020). 
The student design workshop was carefully set up and assessed. One of the main outputs was a design proposal that was presented by each group at the end of the week. The proposals were evaluated by jury members, including university lecturers and architects. A post-evaluation questionnaire was conducted to assess the effectiveness of the workshop. Other researchers also conducted surveys to evaluate the effect of design courses or workshops (Dobbelsteen \& Linden, 2007; Tunçer, 2009).

\section{Method}

\section{Student Group Division}

There were in total 33 students taking part in the workshop. Eighteen of them were from HAU, ten from NUCE and five from TUD. The students taking part in the workshop were both bachelor and master architecture students. All of the TUD students were doing their master study. The majority of the Vietnamese students were undergraduates. Since there was a variety in the experience level and cultural background of students, the group division rule was such that every group had students from all universities and that each group had students from the $3^{\text {rd }}$ year of study until master students. Initially, there were 8 groups of 4 to 5 students. However, due to the absence of some students on the first day of the workshop, the students were re-divided into 6 groups of 5 to 6 students. There were 5 TUD students in total, so there was one group (group number 2) that had no TUD student.

\section{Activities in the Workshop}

The Vietnamese and Dutch students have different backgrounds and have learnt different approaches to sustainable architecture. Vietnamese students have a deeper understanding of the local housing typology, local climate and traditional design measures. TUD students are master students who have more experience in and knowledge of technology and energy efficiency in particular. Therefore, the students were given reading materials prior to the workshop, so they could learn from each other's expertise.

Figure 1 describes the activities of the workshop over the week. The workshop was divided into 3 main stages. In the first stage, the students analysed and discussed the potential and challenges of their own case. During site visits and design brief sessions, the students talked to house owners about their wishes and they asked mentor architects about specific issues of the projects.

During the second stage, the groups brainstormed and defined their design concept, discussed with each other and with the mentors how these design concepts can benefit the whole plan of the proposal. Feedback and discussion were extensively applied. In this stage, the students also attended the GASC conference to obtain new ideas. The main theme of the conference was "sustainable and energy-efficient housing". Participating speakers were professors and lecturers from the three universities. They presented the latest research on sustainable approaches for housing in the Dutch and the Vietnamese contexts. 


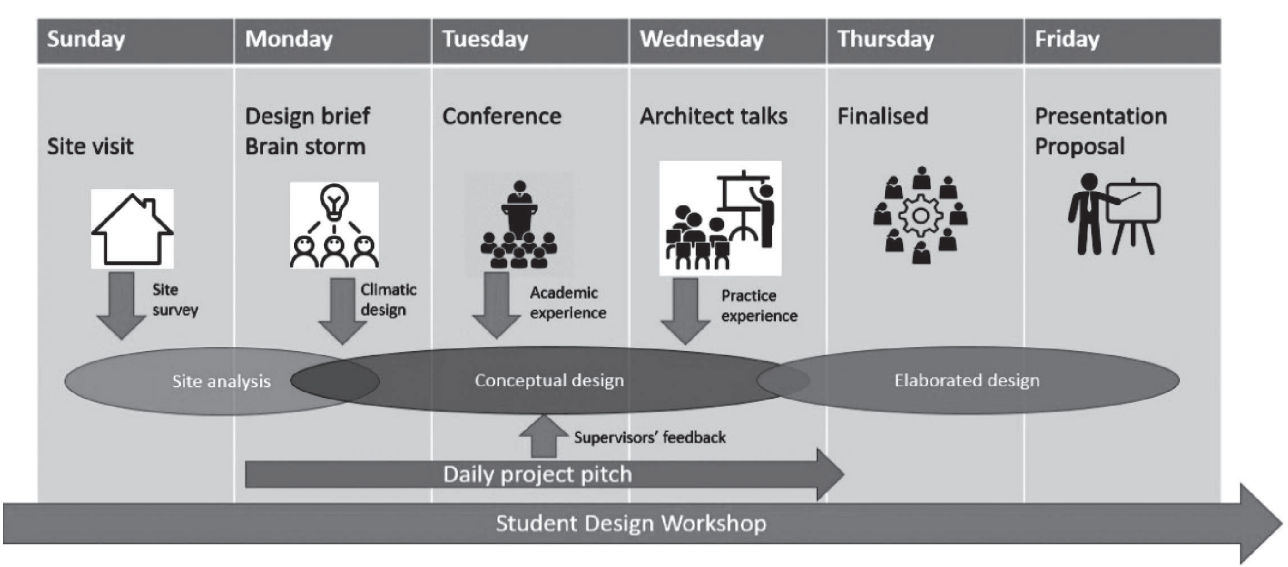

Figure 1. Student design workshop progress (author's graphic)

The last stage consisted of architects' talks, where practical Vietnamese housing projects were introduced. Informed by these, the groups finalised the idea into a specific redesign of a house. Again, difficulties in translating ideas into solutions were being discussed and solved with the help of the mentors.

Design proposals were assessed by a jury of experts in terms of design, thermal and energy performance, and sustainability. After the workshop, the students were asked to complete a questionnaire to evaluate the implementation of the student design workshop and describe their own experiences taking part in this event. The results are given in this chapter.

\section{Constructive Alignment of the Workshop}

The set-up of the workshop was based on constructive alignment, a theoretical concept for teaching and learning in higher education (Biggs, 1996). The main idea of the concept is to align the learning objectives with the teaching/learning activities and the final assessment. Table 1 presents the content of this triangular relationship.

The learning objectives of the student design workshop were to teach the student sustainable design applied to the specific case of Vietnamese tube houses. The students were expected to learn about sustainable design strategies through literature and lectures, to understand and analyse the current context of these cases, including its potential and challenges, to apply the sustainable design measures and integrate them into the proposal, then to present and evaluate the qualities of their proposal.

Table 1

Constructive Alignment of GASC 2019 (author's graphic)

\begin{tabular}{lcc}
\hline \multicolumn{1}{c}{ Learning objectives } & $\begin{array}{c}\text { Teaching and } \\
\text { learning activities }\end{array}$ & Assessment \\
\hline $\begin{array}{l}\text { Understanding the context (Vietnamese culture, } \\
\text { housing typology, the cases) }\end{array}$ & $\begin{array}{c}\text { Site visit } \\
\text { Design brief }\end{array}$ & - \\
\hline $\begin{array}{l}\text { Understanding Dutch approaches to sustainable } \\
\text { homes }\end{array}$ & $\begin{array}{c}\text { Conference } \\
\text { Design brief }\end{array}$ & - \\
\hline
\end{tabular}


Continuation of Table 1

\begin{tabular}{lcc}
\hline Understanding bioclimatic design in Vietnam & $\begin{array}{c}\text { Conference } \\
\text { Design brief } \\
\text { Architect talks }\end{array}$ & \multicolumn{1}{c}{-} \\
\hline $\begin{array}{l}\text { Analysing and applying design measures } \\
\text { Designing the proposal }\end{array}$ & $\begin{array}{c}\text { Group work } \\
\text { Daily project pitch }\end{array}$ & $\begin{array}{c}\text { Formative } \\
\text { assessment }\end{array}$ \\
\hline $\begin{array}{l}\text { Presenting outcomes (presentations, posters and } \\
\text { physical models) }\end{array}$ & Final presentation & $\begin{array}{l}\text { Summative } \\
\text { assessment }\end{array}$ \\
\hline
\end{tabular}

In addition, the TUD students were expected to learn about the Vietnamese culture and housing context by doing site visits and by reading materials, as well as understanding local design approaches, by attending lectures by Vietnamese researchers and local architects. The Vietnamese students were also expected to learn about the sites even though they already have a background of the Vietnamese context. They were required to learn about integrated design approaches from the TUD professors' lectures and reading materials. During the group work discussions, all students needed to analyse the problems and potentials, and to apply design strategies to their own proposals. They should be able to show their design skills and visualise their ideas through sketches and physical models. Finally, the students needed to learn to present and defend their works in daily project pitches and during the final presentation. The assessments were done through daily supervision and during the presentation sessions.

\section{Set Up of the Questionnaire}

The in-house questionnaire had two main parts. In the first part, the dichotomous questions asked the students if they had learned certain design aspects during GASC 2019 and if they had applied them in their proposals. The aspects asked about were: architecture, urban planning, building technology, floor plans and layout options, sustainability, bioclimatic design, energy, water, materials, greenery, indoor thermal comfort, daylight, ventilation, acoustics, air quality, and user behaviour. The second part, including scaling questions, focused on the experiences of the students with the different activities happening during GASC 2019. The activities were: site visits, introduction speeches, Vietnamese architect talks, the GASC 2019 conference, design supervision, student group work, cultural/networking activities, and the final presentation of the student groups. There was also room for the students to give feedback to the organisers.

\section{Research Findings}

\section{Evaluation of Teaching Activities}

There were 28 questionnaires collected after the workshop. Fifteen of them were from HAU students, nine from NUCE and four from TUD (Figure 2). As mentioned in the method section, the students taking part in the workshop were both bachelor and master architecture students. 


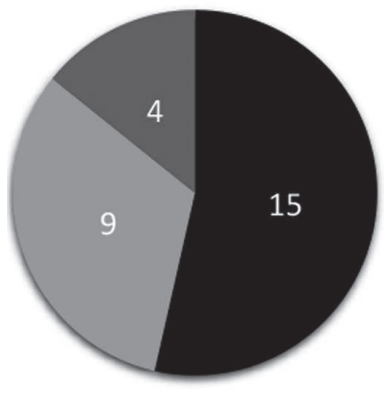

- HAU $\square$ NUCE $\square T U D$

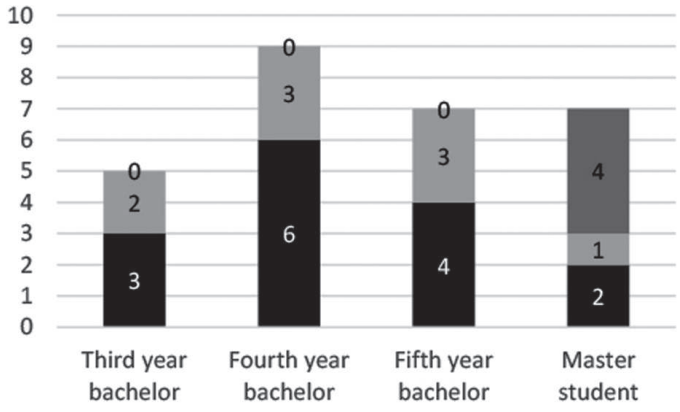

HAU $\square$ NUCE $\square$ TUD

Figure 2. Characteristics of the students participating in the questionnaire

Students were asked if they had taken part in the projects and if they could indicate how much they had learned in each activity by replying "take part only", "learn something" or "learn a lot". The participation rate and the indication of the students are shown in Figure 3.

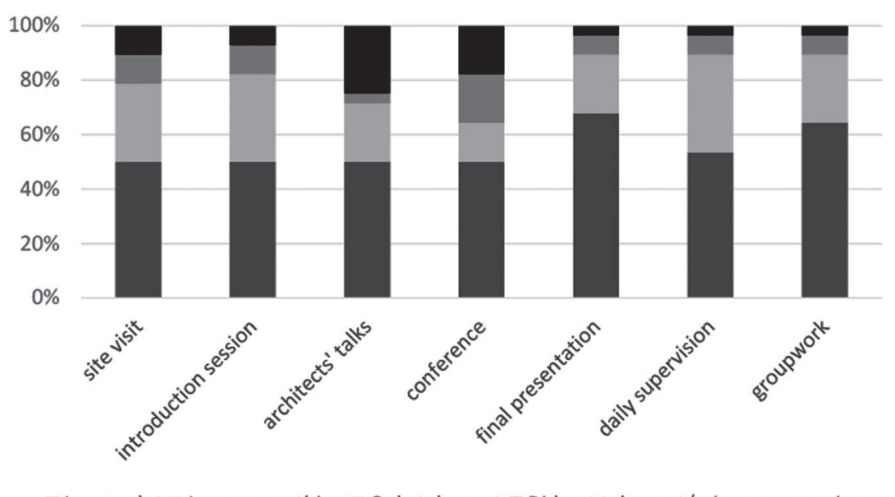

- Learn a lot $\mathbf{m}$ Learn something $\mathbf{m}$ Only take part $\mathbf{a}$ Did not take part/miss some session

Figure 3. Participation rate and indication of knowledge gained from different activities

Many activities had a participation rate above $90 \%$, except for the architect talks and the GASC conference. In any event, at least $50 \%$ of the respondents stated that they took part and learned a lot from those activities. Ninety percent of the students learned something from the daily supervision, student group work and final presentation. These were all interactive activities where the students discussed within their group and had question-and-answer sessions with either supervisors or jury members. The learning rate was lower for activities that had less room for discussion and feedback, such as the introduction session and the conference. It is noted that the architect talks were considered successful with a high learning rate of $71 \%$ compared to the participant rate of $75 \%$.

Grouping students of different years of study together not only maintained balance between groups but also created an environment where younger students could learn from senior students. Figure 4 shows the learning rate of the students in different activities in different educational stages. Students in their $3^{\text {rd }}$ and $4^{\text {th }}$ bachelor year were more likely to learn from peers during the group work. However, last-year bachelor students 
and master students had more experience and learned more from the conference, architect talks and the final presentation. The student learning rates from daily supervision were similar. In general, such a workshop can create good opportunities for all the students to learn, although the senior students with more experience might catch up with the work and benefit more from the different activities.

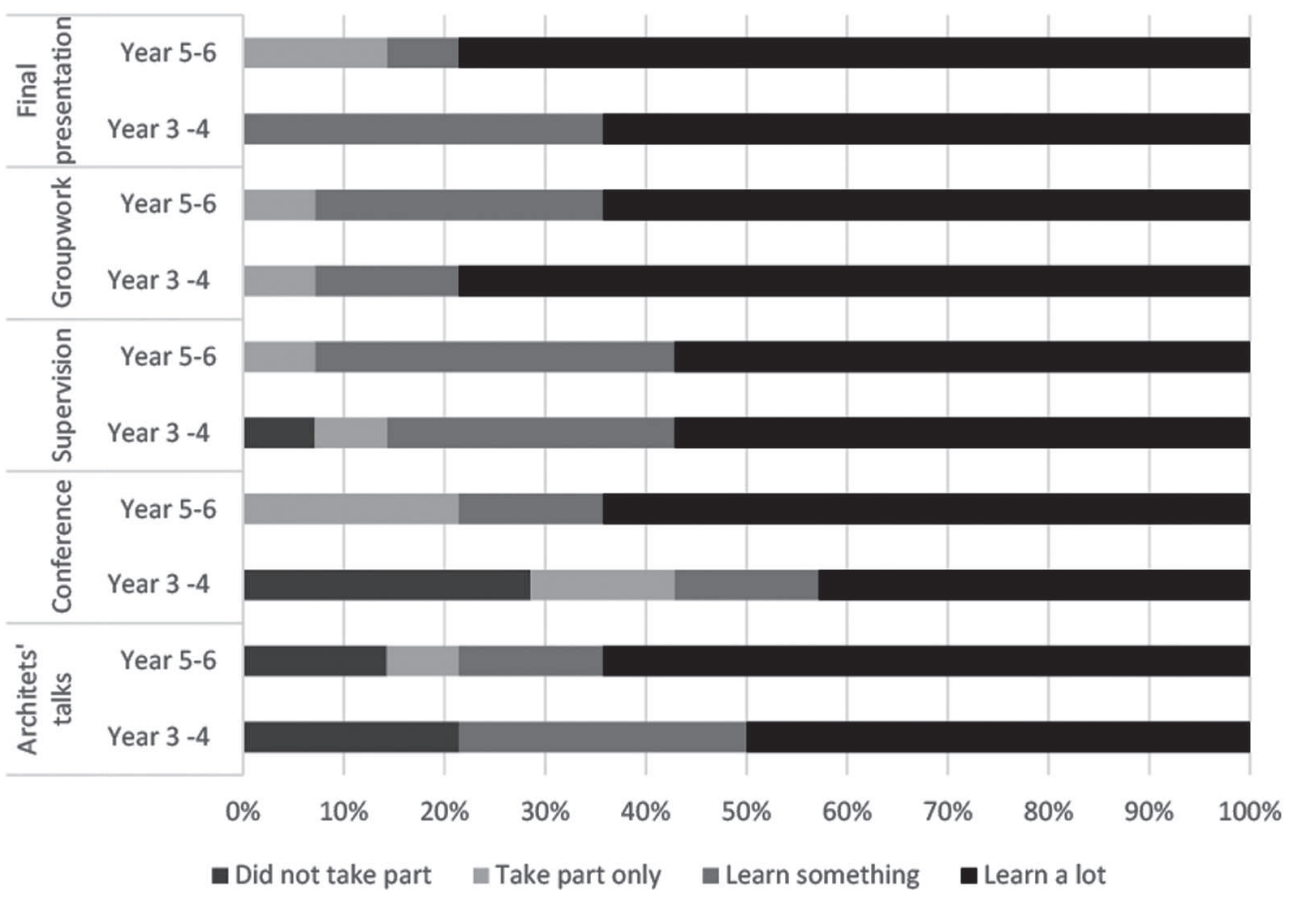

Figure 4. Learning rate of 2 student groups $\left(3^{\text {rd }}\right.$ and $4^{\text {th }}$ year bachelor students, $5^{\text {th }}$ year bachelor and master students)

\section{Evaluation of Design Topics}

\section{Questionnaire results}

The students indicated whether they had learned and applied certain aspects in the design workshop. The descriptive results are shown in Figure 5. There were 6 general aspects asked about: architecture, urban planning, building technology, floor plans \& layout, sustainability and bioclimatic design. According to the results, the students were more likely to learn about architecture and sustainability in general (96\%) rather than urban planning $(54 \%)$. Although urban planning is part of sustainable architecture, the fact that the students investigated a specific case of a private house explains why urban planning was considered not so relevant. Knowledge of building technology, layout and bioclimatic design were gained by more than $80 \%$ of the students. It is worth noting that building technology learning and applying was slightly higher with $89 \%$, while it was $82 \%$ for layout and bioclimatic design. This indicates the benefit of having experts from TUD as supervisors and lecturers, as well as background knowledge from the 
TUD students on the overall outcome of the workshop. TUD students themselves responded that they had learned more about building technology and that they had applied that to the project.
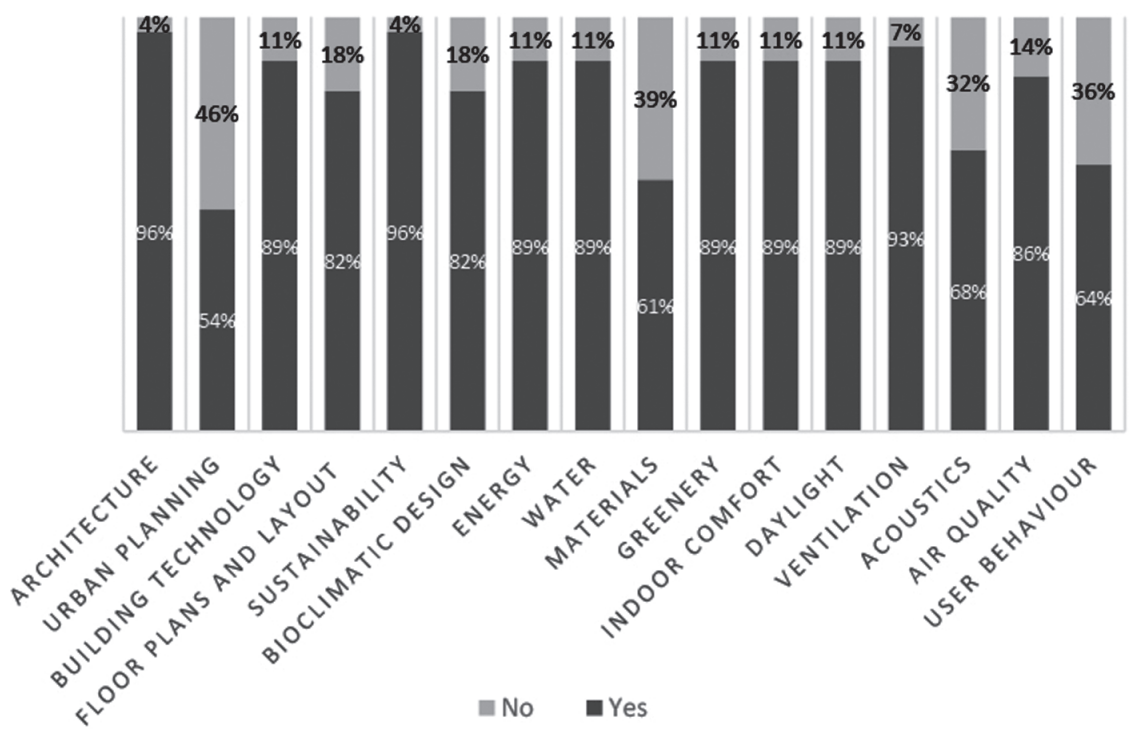

Figure 5. Rates of student that had learned and applied different aspects from the workshop

Specific aspects of sustainable design were also investigated. The results show that the students learned both about bioclimatic design aspects such as using plants and trees, daylight and natural ventilation, air quality, as well as about sustainability aspects such as energy and water management. The positive response rate was around $90 \%$. However, not all the topics were covered in the workshop. The students reported less learning and applying knowledge of sustainable materials, acoustics design and user behaviour. The lack of investigation might be due to the limited time frame of the workshop and the complex application of the three factors.

\section{Workshop results of applied strategies}

The student groups applied design strategies that they acquired from the materials provided, the conference, and the actual projects of the Vietnamese architects, on their own projects. Table 2 below summarises which design strategies were included in the final outcomes.

The most popular design measures were solar shading, greenery, photovoltaics (PV) and rain water collection, which were applied by all groups. The first two are wellknown design measures. They exist in traditional Vietnamese architecture. Using PV was favourable despite a questionable cost-benefit evaluation in Vietnam. The potential of PV is promising, nonetheless, because there is ever more research on increasing the efficiency of PV and lowering its production cost. A solar thermal collector was a lowcost measure to reduce the energy demand for domestic hot water (DHW) but was seen only in the proposal of group 1. The use of solar thermal can be integrated in the PV system, as a photovoltaic thermal hybrid solar collector (PVT). 
Table 2

General Overview of Applied Strategies

\begin{tabular}{lccccc}
\hline \multicolumn{1}{c}{ Strategies } & Group 1 & Group 2 & Group 3 & Group 5 & Group 6 \\
\hline Solar shading & $\mathrm{X}$ & $\mathrm{X}$ & $\mathrm{X}$ & $\mathrm{X}$ & $\mathrm{X}$ \\
\hline Greenery & $\mathrm{X}$ & $\mathrm{X}$ & $\mathrm{X}$ & $\mathrm{X}$ & $\mathrm{X}$ \\
\hline Courtyard/Lightwell & $\mathrm{X}$ & $\mathrm{X}$ & $\mathrm{X}$ & $\mathrm{X}$ & - \\
\hline Solar chimney & $\mathrm{X}$ & - & - & $\mathrm{X}$ & $\mathrm{X}$ \\
\hline Geothermal cooling & $\mathrm{X}$ & $\mathrm{X}$ & - & $\mathrm{X}$ & - \\
\hline PV & $\mathrm{X}$ & $\mathrm{X}$ & $\mathrm{X}$ & $\mathrm{X}$ & $\mathrm{X}$ \\
\hline Solar thermal & $\mathrm{X}$ & - & - & - & - \\
\hline Rainwater collection & $\mathrm{X}$ & $\mathrm{X}$ & $\mathrm{X}$ & $\mathrm{X}$ & $\mathrm{X}$ \\
\hline Waste recycling & - & $\mathrm{X}$ & - & - & - \\
\hline Insulation & - & - & $\mathrm{X}$ & $\mathrm{X}$ & - \\
\hline Elevated roof & - & $\mathrm{X}$ & $\mathrm{X}$ & $\mathrm{X}$ & - \\
\hline Natural ventilation & $\mathrm{X}$ & $\mathrm{X}$ & - & $\mathrm{X}$ & $\mathrm{X}$ \\
\hline
\end{tabular}

Due to the high annual rainfall, rainwater collection has a great potential in Vietnam. The lack of existence of such a measure in contemporary housing projects can be explained by the lack of space for a water tank in a modern house, the low water price and hence low economic benefit. However, in a sustainable housing project, if possible, such a design measure should always be included.

A courtyard, or its smaller version, a light-well, was also applied by most groups. Courtyards and open spaces are important components in traditional dwellings. They provide daylight, natural ventilation, fresh air and social space in a house. They did not exist in the houses investigated, even including house number 3 with the largest plot size. Group 1 and group 3 could only integrate a small light-well in the house, and group 6 had no courtyard/light-well in the proposal because of their small site.

\section{Discussion of workshop results}

The evaluation results from the questionnaire and the workshop outcomes were aligned with each other. Popular design strategies applied, concern bioclimatic aspects such as solar shading, natural ventilation, greenery, cooling, indoor environment and energy productions (PV, solar thermal). They are also shown in the questionnaire responses as most students learned something on bioclimatic design, energy, water, greenery, comfort, daylight, ventilation and air quality. Urban planning, sustainable materials and user behaviour were among the aspects of which students learned less, and they were also absent in the design proposals.

The students indicated that they learned about technology and energy saving. However, the measures that make use of solar energy were not clearly integrated. While all groups chose to use PV to generate electricity, only one group considered the use of solar thermal, which can also be integrated into PV. Three out of five groups proposed to have a solar chimney but the design of such a system was simple and lacked explanation.

The main objective of the workshop was to teach the students about sustainable design strategies and how to apply the strategies into the proposal. Figure 6 shows the learning rate and application rate of different design aspects by the students. We divided the students into two main groups, junior students of year 3 and 4, and senior students of year 5 and 6 (master students). Junior students generally learned more from the work- 
shop than the senior students. The junior students claimed a learning rate of $100 \%$ in 9 out of 16 categories. This response was expected because the senior students are more experienced and already have part of the knowledge. However, the number of senior students who learned from the workshop is still high, which indicates that knowledge has been transferred to the students.

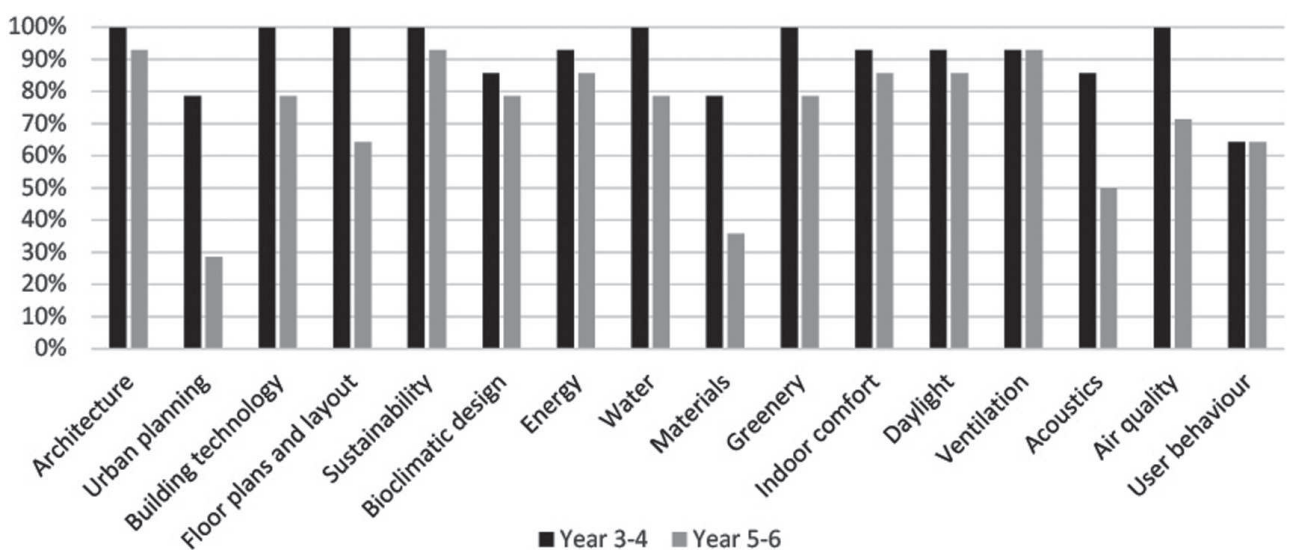

Figure 6. (a) Learning rate and (b) application rate of junior and senior students

In architecture and bioclimatic design parts, or indoor comfort, daylight and ventilation, the learning rate of both student groups are high and similar to each other. These aspects are widely embraced by the students because they are closely connected to the design process and are often easier to present in the design proposal. Sustainable materials, acoustic and user behaviour were either not covered enough during the workshop or less attractive to the students. Both learning rate and application rate for these factors are lower, compared to the others, especially for the case of senior students. It could also be due to the high level of detail and the technical level for knowledge on materials and acoustics. The abstract idea of user behaviour might have had little influence on the design process.

Regarding resources, energy efficiency and water usage were the two most popular measures that most students learned about and applied to their project. Since energy efficiency was one of the key missions in the design brief, it was often discussed during the workshop. In the final output of the workshop, it was translated to the presence of PV, solar thermal, and active cooling measures. Rain water collection was introduced during the 1-hour talk of the two local architects. The presentation of how the architects brought their ideas to real buildings was a real inspiration to the students. This suggests a future workshop should involve more practical examples for the related topics.

\section{Evaluation of the Assessment of the Projects}

The formative assessment of the workshop was mainly done through the daily project pitches. The summative assessment was the final presentation on the last day. During the 5-minute pitches, the students practiced presenting their ideas through sketches and models. The pitches often consisted of a problem statement and proposed measures. Student groups could give feedback to each other, so they could both analyse and reflect 
on the pros and cons of all the cases. Most groups did this part well. However, there was one group in which the ideas and discussion were dominated by a senior student. The junior students in that group did learn from the more experienced one, but they did not learn to reflect and give feedback, as observed by the mentor. This problem is sometimes seen in the East-Asian culture, where hierarchy is important. This behaviour should however be avoided in such workshop activities. In this specific case, the relevant student group was preselected from a group of friends. This suggests that the selection process of students in the future should avoid clumping of friends, and the difference in student backgrounds should not be too big.

At the end of the week, the students presented their final product in front of a jury. The students demonstrated their ability to do research on the case studies and the design measures. They were also capable of utilising the sustainable design principles within the existing structure, considering the owners' wishes. As winner, the jury selected the proposal that according to them integrated best the sustainable design strategies and the aesthetic aspects, as well as functional aspects of the house. All groups proved that the students learned from sustainable principles and that they applied these to the design of existing tube houses.

\section{Students' Feedback on the Workshop}

The students provided feedback to the organisers to enhance the quality of future events. Positive comments often included the diversity of the student backgrounds, participation of practice architects and a good workshop plan. Things named to be improved were the language barrier and student selection.

The diversity in nationalities, universities, and experience of the students was one highlight point of the workshop. The TUD students could learn from the Vietnamese culture, the different design approaches from a different climate region, the local methods of construction and materials. On the other hand, the Vietnamese students could learn from novel technology and various technical skills from the experienced TUD students.

The presence of local architects from commercial practice through the talk show activities, supervision and final presentation was highly appreciated. They provided guidance and a more practical way to approach a project. Lessons learned from their past projects were very helpful to the students, especially in the later part, when the students transferred their ideas to architectural drawings. Some students indicated that more involvement of architects was desired.

However, there were still some shortcomings that need to be addressed in the future. These mainly refer to the student selection process. The students selected in some cases had insufficient English language proficiency, communication skills and group work skills. The problem often related to the junior students with lack of experience and skills. Solution for this issue is that there should be only one recruitment party to select the students from all over the university. In this workshop, each of the universities sent students selected by their own; the only standard and criterion was the year of study.

Another problem was the fact that the number of TUD students was small compared to Vietnamese students. Vietnamese students had little chance to learn from their foreign peers. The large number of group members of 5 to 6 even worsened the situation. The communication between the groups was also more difficult as the Vietnamese students tended to speak Vietnamese to each other. 


\section{Conclusion}

GASC 2019 was an international event aiming at bringing architecture students from Dutch and Vietnamese universities together to work on sustainability projects. The main objective of the workshop was to help the students learn sustainable design skills and strategies and to have them apply these in real housing projects in Vietnam. During the workshop week, the students were exposed to many activities, including site visits, an international conference on sustainability, lectures by local architects, daily supervision from international experts and a final presentation day. A post-workshop questionnaire was developed to assess the quality of the workshop. Results have shown that most activities were successful in transferring sustainable knowledge to the students. The results from the questionnaire were in line with the workshop outcomes, the design proposals. Both of them have shown the capabilities of the students to understand sustainable theory, to analyse design strategies in the specific cases and to apply that knowledge into the design proposals. The design process of the students was repeated every day with project pitches and the students reflected on their own projects as well as on works of others.

More junior students claimed to have learned sustainability design measures from the workshop rather than the senior ones, because less experienced students had more to learn. However, most of them showed a high learning and application rate. Students learned more about bioclimatic designs and related topics such as daylight, natural ventilation, indoor comfort and greenery, as these were better covered during the workshop and easier visualised in the design proposal. Sustainable aspects of energy efficiency and water usage were also of great interest as these were applied widely in the design proposals, including PV and rain water collection.

The student selection process was the main issue for this GASC 2019 workshop. It is suggested that the students should be selected in terms of quality and communication abilities. Applications for the workshop are recommended to be handled by one party only. The students should also have a similar background or year of study. There was an incident of a dominant student that prevented discussion and learning opportunities for younger students. The proportion of foreign students and local students should also be taken care of, so students can learn more from each other. For future events, more involvement of architects from practice is recommended. The students showed their interest in practical projects, especially from local architects.

\section{References}

Biggs, J. (1996). Enhancing teaching through constructive alignment. Higher Education, 32(3), 347-364. Retrieved from https://doi.org/10.1007/BF00138871

Cross, N. (1982). Designerly ways of knowing. Design Studies, 3(4), 221-227.

Dobbelsteen, A. v., \& Linden, K. v. d. (2007). Self-directing learning - getting students to learn effectively about smart and bioclimatic design. Proceedings PLEA, 816-821.

Dreyfus, H., Dreyfus, S. E., \& Athanasiou, T. (2000). Mind over machine. US: Simon and Schuster.

Heasly, B., Lindner, J., Iliško, Dz., \& Salīte, I. (2020). From initiatives, to insights, to implementation of the sustainability and securitability agenda for 2030. Discourse and Communication for Sustainable Education, 11(1), 1-4. 
Kolb, D. A. (2014). Experiential learning: Experience as the source of learning and development. US: Pearson Education.

Lawson, B. (2006). How designers think. UK: Routledge.

Nguyen, H. T., Skitmore, M., Gray, M., Zhang, X., \& Olanipekun, A. O. (2017). Will green building development take off? An exploratory study of barriers to green building in Vietnam. Resources, Conservation and Recycling. Retrieved from https://doi.org/10.1016/j.resconrec.2017.08.012

Reigeluth, C. M. (1983). Instructional design theories and models: An overview of their current status. UK: Routledge.

Tunçer, E. B. (2009). The Architectural Information Map: Semantic modeling in conceptual architectural design. Delft: Delft University of Technology.

van Dooren, E., Boshuizen, E., van Merriënboer, J., Asselbergs, T., \& van Dorst, M. (2014). Making explicit in design education: Generic elements in the design process. International Journal of Technology and Design Education, 24(1), 53-71. Retrieved from https://doi.org/10.1007/s10798-013-9246-8

Waks, L. J. (2001). Donald Schon's philosophy of design and design education. International Journal of Technology and Design Education, 11(1), 37-51.

Correspondence relating this article should be addressed to Phan Anh Nguyen, Delft University of Technology, Delft, the Netherlands. Email: P.A.Nguyen@tudelft.nl 